\title{
A Brief View of Practice Ontology Aesthetics in the Context of Contemporary China
}

\author{
ZHU Li-yuan \\ Fudan University, Shanghai, China
}

\begin{abstract}
In recent years, Practice Ontology Aesthetics takes shape in academic discussion and argument. The introduction of Practice Ontology Aesthetics occurred in the course of introspection of Practice Aesthetics in modern China, in which the existence dimension in Marxist concept of practice was of great significance to breaking the theoretical limitation of present Practice Aesthetics. Therefore, in terms of the distinctive context of Chinese contemporary aesthetics, the introduction of Practice Ontology Aesthetics from the theoretical perspective of Marxist existentialism offers a possible way to break the current aesthetics and represents a multiple academic pursuit of Marxist, Chinese and modern aesthetics.
\end{abstract}

Keywords: Chinese contemporary aesthetics, Practice Aesthetics, Practice Ontology Aesthetics

Since 2009, Mr. Dong Xuewen and other people continuously published articles, criticizing and questioning Practice Ontology Aesthetics. We made some responses to them, and consequently, a controversy on the Practice Ontology Aesthetics had formed in academic circles. We had already conducted a preliminary summary and fully showed our viewpoint and attitude toward this issue. ${ }^{1}$ Although the speech from the opposite side was not entirely based on academic issues for discussion itself, during which there was no lack of political accusations and criticism, we still tried our best to present the facts and the truth, to clarify our basic views on theoretical level. Overall, despite the controversy focuses on the Practice Ontology Aesthetics, it also relates to a series of questions, including how to accurately understand the thought of Marxist Aesthetics, as well as how to promote the development of Chinese contemporary aesthetics. Thus, it is necessary to rethink of Practice Ontology Aesthetics and its basic thesis for promoting the research on Marxist Aesthetics and improving the development of Chinese contemporary aesthetics in the context of contemporary China.

\section{Part 1}

The development of Chinese contemporary aesthetics, from the Great Aesthetic Discussion in 1950s and 1960s to the Aesthetics Popularity in 1980s, has undergone a long way. Some basic schools of contemporary Chinese aesthetics gradually formed in the discussion, and Practice Aesthetics also generated among them. We can say that the basic direction of the development of contemporary aesthetics was established after two big

ZHU Li-yuan is a Distinguished Professor of Department of Chinese Language and Literature in Fudan University.

${ }^{1}$ We still sincerely receive and look forward to serious, truly academic and nonpolitical criticism, however, we will not continuously answer to the related issue referred by this essay and the former counter-criticism essays if we don't see some new and good criticism from Mr. Dong. See Zhu Liyuan, \& Li Yongqing, "Counter-criticism to Recent Criticism about Practice Ontology_A Primary Conclusion of Mr. Dong Xuewen’s Criticism”, Journal of Shanghai University (Social Science Edition), No. 1, 2011. 
controversies since the founding of China. Concentrating on the problem of the Essence of Beauty, it is well-known that four major schools of contemporary Chinese aesthetics formed in the Great Aesthetic Discussion in 1950s and 1960s, including Subjective aesthetics represented by Lv Ying and Gao Ertai, Objective aesthetics represented by Cai Yi, Subjective and Objective unification aesthetics represented by Zhu Guangqian and Objective social aesthetics represented by Li Zehou. In my opinion, considering the specific context of China in that time, though they have different views and ideas in understanding and applying Marxism, the nature of all of them still belong to Marxist Aesthetics. After the Great Cultural Revolution, the four major schools have more or less developed by learning and studying Economic and philosophical Manuscripts in1844of Marx. Besides the side of Objective, the opinions of the other schools are changing to be close to each other. And Objective social aesthetics of Li Zehou finally developed into Practice Aesthetics (although Li himself didn't accept the formulation of "practical aesthetics” until 2004). In late 1980s, for various reasons, Practice Aesthetics gradually rises to mainstream while the influence of the other three schools has been reduced.

Practice Aesthetics, as one of the main schools of Chinese Marxist Aesthetics, has been in a debate with the other thoughts since its occurrence. Reflecting from theoretical foundation, thinking framework and logical conclusion, some scholars in this field put forward some theoretical views, such as Stepping into Post-Practice Aesthetics and The End Theory of Practice Aesthetics since 1990s. Among them, the earliest one is Liu Xiaobo, who challenged Le Zehou in late 1980s. ${ }^{2}$ When in 1993, Chen Yan published the essay On the Theory of Accumulation and Theory of Mutation, ${ }^{3}$ rethinking of Practice Aesthetics from criticizing the Theory of Accumulation of Li Zehou. Then in 1994, Yang Chunshi published the essay Stepping into Post-Practice Aesthetics, ${ }^{4}$ criticizing Practice Aesthetics from ten points. Subsequently, Zhang Hong and Pan Zhichang also stated several criticisms on Practice Aesthetics from different perspectives. Other scholars, including Yang Chunshi, proposed their statements to construct Transcendence Aesthetics, Being Aesthetics and Life Aesthetics in succession. Objectively speaking, these criticisms did notice the theoretical limitations of traditional Practice Aesthetics, and some points have its inherent rationality. Meanwhile, some scholars, who still upheld the basic idea of Practice Aesthetics, started to reflect the defects and limitations of it, tried to rethink how to further develop it and explore its possible breakthrough from a new level. I also belong to one of them.

I always approve the overall thought of Practice Aesthetics and highly respect Li Zehou as the founder and main representative of Practice Aesthetics. In my opinion, Li Zehou is one of the greatest philosophers and aestheticians with the highest achievements and biggest contribution in modern China. He founded the whole philosophical framework for Practice Aesthetics, constructed the basic theoretical ideas, put forward a set of new academic category and made logical reasoning and elaboration systematically and deeply. For a long time, I insisted Li's doctrine and defended for him in debate with Post-Practice Aesthetics. And now I do not think Li's idea is obsolete or should be replaced or abandoned, but still has possibility to be developed. After ten years of learning and thinking, I should admit that Li's opinion is not perfect or flawless, but has some serious academic deficiencies and limitations as follows:

\footnotetext{
${ }^{2}$ Liu Xiaobo, Criticism of the Choices-A Conversation with Li Zehou, Shanghai People’s Publishing House, 1988.

${ }^{3}$ Chen Yan, On the Theory of Accumulation and Theory of Mutation, Academic Monthly, (5), 1993.

${ }^{4}$ Yang Chunshi, Stepping into Post-Practice Aesthetics, Academic Monthly, (5), 1994.
} 
Firstly, its philosophical foundation retreated from monism to historical dualism of Two Ontology. Mr. Li, who originally insisted on historical materialism of instrumental being, gradually changed his idea into Two Ontology, which means psychological being or feeling being was parallel with or even higher than instrumental being. In fact, this is a deviation from historical materialism. ${ }^{5} \mathrm{Mr}$. Li noticed the criticism from me and made a response as follows:

Recently, there seems to be someone from Shanghai, published an article on Philosophical Research, saying that I firstly speak of instrumental being, and then feeling being-how could I have two beings? He blamed me for violating Marxism materialism. Some people also said that being is the ultimate reality, so how many beings did you have? This questioning was because I have said that both psychological being and measurement are ontological. Did I add these two beings and created four beings? Actually, I have made it clearly that the final being is absolutely the historical being, and it developed into two directions, one is external, which means natural humanization, also called instrumental—social being; The other is internal, which means internal natural humanization. That is called psychological-feeling being, between which feeling is more prominent. So the cultural-psychological structure is also called complex. As for measurement, man exists on measurement. Measurement has a nature of ontology, which is the reliance of people's existence and living. All of above discuss one question - that is anthropological history ontology that concerning all men and all the individuals' living and lasting.

However, the response doesn't seem to be convincing. Historical being, with meaning of final being, just as Mr. Li has repeatedly stressed, could only be one, that is, the instrumental being. Other ones, such as feeling and psychological ones, are all derived, which could not be defined being. If they have to be named beings, they could only be the second or third being, instead of being equal to instrumental being or being divided into two beings externally and internally as Mr. Li said. I did not mean to blame Mr. Li for violating historical materialism, but simply pointed out a fact. I wish I could consult this question with Mr. Li continuously, looking forward to hearing more specific explanation.

Secondly, it doesn't completely overstep the thinking models of the epistemology of subject-object dichotomy from Western modern times, and this is precisely the main obstacle for Chinese aesthetics to make a real breakthrough and development. Mr. Li once stated explicitly in Sense of Beauty, Beauty and Art: The basic philosophical problem of aesthetics is the problem of epistemology, and the central part of which is the sense of beauty. Starting from sense of beauty that is starting from the analysis of dialectics of human's cognition to beauty, that is starting from epistemology, and that is starting from analyzing the problem of objectiveness and subjectiveness, existence and consciousness, which are the basic problem of philosophy. It seems that Mr. Li later changed his idea toward this problem, however, he never clearly renounced or denied the basic idea of placing beauty and sense of beauty in the framework of epistemology.

As we all know, in the 1950s, although four schools of Chinese aesthetics have different opinions, they shared the same idea to the object of aesthetical study, that is namely regard for What beauty is. In other words, all four schools regard pursuing essence of beauty as a self-evident premise in aesthetical study, which is the questioning mode of pure epistemological subject-object dichotomy. Mr. Li’s Practice Aesthetics is no exception. For the question of What beauty is, he thought that beauty is the unity of objectivity and sociality. This answer doesn't deny or cancel the questioning mode of subject-object dichotomy as What beauty is. Fundamentally, it is still in the thinking mode of epistemology, except changing the individual subject, which was named by Zhu Guangqian, into the social subject. It is still the substantial relationship of epistemology

${ }^{5}$ Details in Zhu Liyuan, An Analysis of Two Ontology of Li Zehou’s Practice Aesthetics, Philosophy Research, (2), 2010. 
between subject and object (beauty). In fact, it is a certainty and a presuppose that beauty is a physical being as an object if we admit the questioning mode of What beauty is. Li's answer, in essence, is still an answer of substantiation in subsistent mode of thinking. Such epistemological thinking makes beauty physical and extant. At the same time, it is easy to infer that the sense of beauty is a cognition, a feeling and an experience to the physical and extant beauty. It could not be a fundamental breakthrough to dividing beauty and sense of beauty into the subject-object dichotomy. Although Lectures on Aesthetics in 1980s made some processes in this field, such epistemological questioning mode of subject-object dichotomy still persists.

Thirdly, Li's narrow view toward practice cannot be the real theoretical foundation of Practice Aesthetics. As for the conception of practice, Li thought that practice is only man's material production labor. In his opinion, the category of practice in Marxism only refers to material production labor. Other human activities, such as art and aesthetic activities, are not practice. It is quite a narrow view. According to his opinion, practice is only the process that human, as instrumental being, learn to make and use tools, change the nature, then create and feel the beauty in material practice. In Li's understanding, the world is objective and subsistent, and human beings are subsistent too, although he laid stress on establishing relationships between human and world, and human and human through practice. Therefore, the relationship between human and the world is a relationship of cognition and transform from subsistent subject to subsistent object. It's like a circle that from human obtaining freedom by cognizing and transforming the nature, and then re-cognize and re-transform. In this process, aesthetics generated. But in fact, Practice Aesthetics can never be able to truly solve the problem - how practice, material and utility, transforms into aesthetic, non-utility. Li subsequently submitted the concept of psychological being to solve this problem, but then came into the dilemma of two beings. It should be noted that Li's idea cannot represent all standpoints of Practice Aesthetics, which has different schools internally, instead of a monolith. Different scholars, insisting on the concept of practice, enrich and develop Practice Aesthetics from different angles, and form their own viewpoints. Such as Liu Jigang and Jiang Kongyang, both of whom form different standpoints, which is the starting point for me to rethink of Practice Aesthetics. Especially Mr. Jiang's aesthetic relation theory, which bases on practice theory and centers on creation theory, bring the impact on me straightforwardly and vitally. Practice Aesthetics faces many problems currently, but I believe it remains far from complete. However, if we still insist on epistemological framework of the old subject-object dichotomy, it should probably be difficult to make breakthrough and development. In that way, how can we insist on the basis of practical philosophy of Practice Aesthetics, and meanwhile make some breakthrough, some transformation and some development to its limitation, is the major problem we have long thought of.

At this time, Heidegger's ontological thoughts of phenomenology give us important revelation. Heidegger thought that human beings are not isolated, but being in the world (In-der-Welz-sein). In other words: "this being essentially includes being in the world. So this type of comprehension to being of this being is originally referred to the comprehension on something like the world, or the comprehension on the being of accessible beings in the world." The being exists in the world, which means this being (human) in the world is the fundamental topic of ontology. Heidegger firstly stressed that the word formation of this compound noun indicates that it implies a whole phenomenon. The primary being condition should be seen as a whole, not as a mode of subject-object dichotomy; additionally, the in here of this being doesn't means human (body material) ready exist in the living existence, but refers to a type of being construction, which has a property of existentialism, and this being regards the world as such a familiar place to dwell in and stay in. So this being 
and the world are absolutely not two living existences that coexist or paralleling. Therefore, being itself of this being has ontological meaning to be in the world. It is through the analysis of Dasein, Heidegger illuminated the ontological meaning of the being exists in the world, which emphasized original inseparability between people and the world. Human can not leave the world at the beginning, and it is part of the world; the relationship between human and the world, is not unity after division, but unity at first and without division. Meanwhile, the world has its meaning only for the human, and human can exist only when in the world. Human is in the world, and the world exist only for human. Without human, the world can never exist as the world. This means there is no present individual absolute subject, or present absolute object that diametrically opposed to human. Human and the world cannot be divided in original ontology. Firstly we should decide that human existing in the world is doubtless, and then we can consider other questions. Beyond question, Heidegger's ontological analysis on Dasein contains important thoughts on transcending epistemological thinking mode of subject-object dichotomy. However, instead of Heidegger's Dasein ontology, it is Marx's ontological thoughts, which closely combined with theory of practice, that truly lead us to practice ontology. Heidegger's thoughts are only a mediation or transition in the way to practice ontology. Coming back to reading and studying Marx's work after initial enlightenment from Heidegger, we are glad to find that Marx's theory of practice contains ontological dimension itself, which has a possibility to provide a new perspective for the creative development of Practice Aesthetics. This is the Marxism theoretical foundation for us to raise Practice Ontology Aesthetics, not straightly using Heidegger's ontology as philosophical foundation, as some people impose on us.

\section{Part 2}

Practice is one of the core categories of Marx's historical materialism. There are two clear points presented in Marx's works: Firstly, Marx inherited the tradition from Aristotle to German Classical Philosophy, which practice is in the opposite relation with theory. In this framework, practice, against theory (cognition), is regarded as man's doing (making), behavior, action, living, activity and so on, that is the application and realization of cognition (theory) and the change of real world. Secondly, Marx understood and applied practice in a generalized way from the start. He considered material production labor as the basic meaning of practice, but he had never confined the meaning of practice into purely material production labor. Instead, he deemed that practice also contains human real activities, such as politics, ethic and religion, and other mental production work, such as art, aesthetic and scientific research.

Marx clearly stated: men are not abstract existence isolated the world. Men are men's world. In other words, in original meaning, men and the world are integrated and indivisible. Men cannot even be out of the world for a moment, and they can only exist in the world; similarly, the world also cannot be out of men. It has meaning only for men. Without men, the world cannot be named world. The world can never be an immutable subsistent being that irrelevant and indispensable with men. Men can neither. Those two are being and developing in the process of reality. It is human being's active living process-practice-that combines men with the world, and constructs the real being of men in the world. Therefore, Marx's conclusion, men are men's world, typically reflects modern ontological thoughts. More importantly, those ontological thoughts are based on view of practice and realized by practice. They not only contain ontological thoughts as men are being in the world, but also reveal that men's basic being way is practice. Marx clearly pointed out: men's being is their real living, and essentially, all their real social life is practical. In conclusion, practice, as men's real living process, is the basic way for human being. 
The ontological dimension of Marxist's view of practice concentrated expressed the following idea: men exist, but only as the subject of practical activities; the world exists, but only has meaning as the object of practice. Without practice, the so-called being-in-itself is pointless. Self-evidence in being is dispelled, and practice, as the logical premise of being and the personal premise, has been established. This essentially lay a foundation for several ontological question. Being, seen as self-evident in traditional ontology, would be based on practice ever after, which is the core and fundamental concept of ontology. Thus, the Marxist View of Practice and Ontology tightly integrated with each other. In this context, practice is not only the origin of idea, and also the logical premise of several ontological issues. Therefore, the thought of ontology is not Heidegger's patent, but inherent in Marx's thoughts. Marx's thought of ontology, because of its foundation on his view of practice, was not only earlier but also higher than Heidegger's Dasein Ontology. To explore and think of Marx's practice from ontological dimension, has become the essential basis for us to put forward Practice Ontology Aesthetics. According to all above, through repeated discussion with my graduated students, we gradually formed several basic arguments toward Practice Ontology Aesthetics as follows:

Firstly, practice is the basic way to human's being. The practice here refers to broad life practice, which contains not only material production labor, as basic form of practice, but also a variety of spirit production activities, including art and aesthetics.

Additionally, aesthetics is also one of the basic ways for living and life practice to human. Aesthetical activity is a very important aspect and factor for human to step into a kind of comprehensive and free development, and it is also a high level spiritual needs. It is a further development for the relationship between human and the world from material level to spiritual level, and it also witnesses one of the important living ways — what makes humans human, what makes humans transcend animals and what embodies the essence of human.

Thirdly, aesthetics considers the aesthetical relationship between human and the world and its real development as research object. We deem that, there is no ready-made aesthetic subject and aesthetic object that can be out of specific aesthetical relationship and aesthetical activities. All the aesthetic subject and aesthetic object are generated from specific aesthetical relationship and aesthetical activities. That is, aesthetic object (beauty) and aesthetic subject (sense of beauty) realistically generate only in aesthetical activities simultaneously. In conclusion, Practice Ontology Aesthetics takes aesthetical activities (real development of aesthetical relationship), instead of beauty and the essence of beauty, as the main object and logic start. This is our actual attempt to go beyond the thinking patterns of subject-object dichotomy toward the object of aesthetical study.

Fourthly, replace subsistent mode of thinking with generative mode. We hold that, it cannot solve the basic problem of aesthetic by subsistent mode of thinking of subject-object dichotomy. Beauty could only dynamically generate in real and specific aesthetical activities. And then, the thinking mode of aesthetics changes from What beauty is into Why beauty exists and How beauty comes into being, which reveals aesthetical thinking of generative theory.

Fifthly, aesthetics is a high level realm of life. When in different kinds of social practical activities or dealing with the world, people will form different kinds of unity relations with the world, which are reflected in various levels that people understand their survival practice and the meaning of the universe and life. And then, various levels of realm of life will be formed, among which aesthetic realm is in a high one, because it will transcend individual utility and limitation in a large extent and reach into a relatively free state. 
Practice Ontology Aesthetics understands the concept of practice from the angle of ontology, and regards generalized life practice as man's basic existing mode. It stresses that only in practical activities can people and the whole world be specifically developed. We deem that, this train of thought has vital meaning to break the theoretical limitation of the existing Practice Aesthetics.

Firstly, this train of thought can help us transcend epistemology of subject-object dichotomy in aesthetical research since modern times. Epistemology's way of thinking is centered on subject-object binary opposition. In subjective side, it sets binary opposition between sense and sensibility, soul and flesh; while in objective side, it sets binary opposition between essence and phenomenon, universal and special. Using the mode of binary opposition to explain a variety of aesthetical phenomenon inevitably leads to the way of essentialism. Thus, it makes aesthetic activities, including its subject and object, pulled out from the endless flow of generation, cut down the beforehand condition, in which subject as aesthetic subject and object as aesthetic object, which also means the specific aesthetic relations of human and the real world. Meanwhile, it also cuts down the ontological dimension of aesthetic activities, which means daily activities and life practice of human existence. Therefore, aesthetic activities are narrowed into pure cognitive activities, in which beauty is seen as preexistent and constant aesthetic object while sense of beauty is seen as a reflection or cognition to beauty from forthcoming and constant aesthetic object. For these problems, Practice Ontology Aesthetics tries to base on life practice of ontology, transcends comprehensively the way of epistemology of subject-object dichotomy as above and provide a brand new train to the development of modern aesthetics.

Additionally, we stress that aesthetical study should break the old frame of subsistent theory and establish a new one of generative theory. As mentioned before, the basic standpoint of epistemological aesthetics is to regard beauty as an objective existence and presuppose a constant beauty of living existence; similarly, it also presuppose human as a constant aesthetic subject to be the living existence, so it determines that the main task of aesthetic is to give a definition to beauty and sense of beauty, and hence it is always asking the questions as what beauty and sense of beauty is, or what the essence of beauty is. However, if we start from Practice-Ontology, aesthetic object and subject, beauty and sense of beauty are not constant or living existence, on the contrary, they all realistically generate in specific aesthetic activity and the forming and developing process of aesthetic relation between human and the world. The thought of generative theory will bring new revolution to aesthetic discipline. And then it is necessary and possible to rethink and reform the research object, logic starting, basic questions, category system and theory framework of aesthetic study.

Thirdly, in Practice Ontology Aesthetics' perspective, practice is the basic existing way of human. Art and aesthetics are also a vital and indispensable part of life practice, and also one of the basic being ways and existing ways of human. Practice, the effect of which includes art and aesthetic practice, makes man into man and also makes them develop. Human society is built on endless and colorful life practice, which covers art and aesthetic activities. Human civilization get established and improved by practice. Art and aesthetic activities, as one of the symbols of human civilization, are also developing in the process of human practice. On the other hand, art and aesthetic activities also improve the integral development of human practice and the construction of human civilization. What's more, according to Marxism's argument that human's real being is their real life practice, Practice Ontology Aesthetics stresses that aesthetic activities should be back into human's real life and daily life practice, which has essential meaning to change the current condition that aesthetics is narrowed in the circle of theory and scholars, and to combine it closely with human's real life and mass culture. 
We can say that, insisting on the core concept of practice, the introduction of Marx's ontological horizon gives Practice Ontology Aesthetics the inner character of modern aesthetics and further reflects the contemporary meaning of Marx's aesthetic thoughts.

\section{Part 3}

The direction in which Chinese contemporary aesthetics goes is a problem that all educational circles have been thought of. And our Practice Ontology Aesthetics comes from this context. The inception of Practice Ontology Aesthetics is originally inspired by Heidegger's ontology, and more importantly, from rethinking and re-understanding of Marx's ontological thinking which is closely related to his view of practice. It is the result of long-time thinking and studying toward Chinese contemporary aesthetics and Practice Aesthetics. During the research, many theoretical views were forming in the collective study and discussion with my students. Therefore, Practice Ontology Aesthetics is really the crystallization of collective creation.

Based on the specific context of Chinese contemporary aesthetics, Practice Ontology Aesthetics is proposing and thinking of the possible breakthrough of modern aesthetics in the new theoretical horizon of Marx's ontology, and thus gives expression to the multiple academic pursuit of both Marxism aesthetics, Chinese aesthetics and contemporary aesthetics.

Firstly, during the study, we base on Marx's classical work all the time and insist on making explanation to his work through strict and careful text analysis. And consciously, we put our explanation in the whole Western ideological tradition and the process of fundamental and great theoretical revolution of Marxist Aesthetics, understanding his aesthetical thoughts from the integrality of Marxist's development. Hence, we are opposed to the so-called myth of Two Marx, and also object to place Paris Manuscripts in opposition to Marx's after work. In our opinion, Paris Manuscripts has showed the ontological dimension of Marx's theory of practice, which is exactly consistent with his later ideological development, as well as a strong support to aesthetical establishment today. It makes possible for us to break a dogmatic, tooling and mechanized understanding toward Marx for long time. For this, based on the concept of practice from Marx, Practice Ontology Aesthetics puts forward and thinks of some aesthetical problems from ontological dimension and this reflects a distinct theoretical pursuit of Marxist Aesthetics.

In the next place, exploring and discussing the ontological dimension of Marx's theory of practice undoubtedly provides extremely important theoretical enlightenment to the establishment and development of Chinese contemporary aesthetics. As mentioned above, since 1990s, educational circles have raised some critics to practice aesthetics. Frankly speaking, some of them have their reasonable aspects, which actually expose our long-term unilateral and narrow tendency toward Marx and his concept of practice. Practice Ontology Aesthetics emerges in this specific context, which seriously thinks of Marx's concept of practice, and puts a high value on the challenge from Post-Practice Aesthetics to Practice Aesthetics, tries best to deal with these critics and doubts, and on this basis think of the breaking way for Chinese contemporary aesthetics. During this process, we attach great importance to the theoretical results that Practice Aesthetics has already reached, and fully considerate of the reasonable comments that Post-Practice Aesthetics made to Practice Aesthetics, attempting to raise our own theoretical thoughts on the basis. At this point, Practice Ontology Aesthetics shows respect to this specific Chinese context. From our perspective, it is also the specific context that our Chinese aesthetics should face and respect for development in the future. 
At the same time, in theoretical construction, we make efforts to get theoretical thinking and traditional Chinese aesthetics cross-referred and interpenetrated with each other. Although some arguments from Practice Ontology Aesthetics, like aesthetic is a base kind of life practice, or aesthetical realm is a high level realm of life, is expounded from the concept of practice, all of them still have deep-level ideological background of traditional Chinese aesthetics. Because of these efforts, we hope to highlight the unique ideological character that Practice Ontology Aesthetics has as contemporary Chinese aesthetics. We also hope it can inherit the tradition of Chinese classical aesthetics, show the unique logic way and pursuit of Chinese in aesthetics and become a beneficial exploration for the conversation between tradition and modernity in Chinese aesthetics, then provide new possibility for the communication, interaction or fusion to Chinese and Western aesthetics, and for sinicizing aesthetical theory. So far, we have only done a tentative exploration. Much more work is needed.

To our minds, future development of Chinese aesthetics should base on the overall development of Chinese aesthetics and the historical progress of localization of Marxism in China, which shows the specific context of modern China and also raise unique Chinese aesthetical problems. Practice Ontology Aesthetics makes some preliminary attempts in this aspect, but it is not enough at all.

Thirdly, we don't deny that Practice Ontology Aesthetics has ever had some inspirations from Heidegger's basic thoughts of ontology. And this encourages us to start thinking from ontological perspective, to re-study and re-explain Marx's Paris Manuscripts and other works and also makes us find that Marx's idea itself contains ontological dimension, which was not paid enough attention to by the circle of literary theory and aesthetics during the research and reading. In the re-studying, we're very glad to find that the circle of philosophy in China has ran ahead of us, a majority of whom actually reach an agreement to a certain extent, that there objectively exists ontological thoughts in Marx's works including his later writings, and they see Marx's ontological thoughts as the main mark of his philosophical revolution. Objectively, this supports greatly for Practice Ontology Aesthetics. What's more, through the explanation from ontology, it can just observe Marx from the whole development of the western philosophical tradition and further, it can show the modern meaning of Marx's thoughts, and can also make the pioneering status during the modern transformation of western traditional philosophy more prominent. In this academic context, from our subjective perspective, the occurrence of Practice Ontology Aesthetics also has the intention to pursue modern aesthetics' ideological character, whose thoughts on generative theory of aesthetics, or the thoughts of logic priority in practical activities, reflect kind of modern orientation of aesthetics. All of them are based on the ontological dimension of Marx's concept of practice.

There is no denying that Practice Ontology Aesthetics has not been mature at all so far, and it has not yet been an integral system, which has a lot of imperfections. Some basic thoughts are not carried through in all problems and also contain pondering space and more possibilities to be changed or improved. So we always stress that, it is only stepping to practice ontology aesthetics presently, and the way of stepping to can be long and even endless. Practice Ontology Aesthetics is open but not close, and it is ongoing and unfinished. So criticism and correction from academic circle is a welcome to us. Just as we mentioned before, although the current argument of Practice Ontology Aesthetics is not completely based on the academic problem itself, some of which even has a touch of political criticism, it is still beneficial for us to deeply learn and further think of Marx's aesthetics thoughts and Practice Ontology Aesthetics. 
In the discussion, we go over Marx's classical works again and more insist on the theoretical confidence to Practice Ontology Aesthetics. We believe that, the modern ontological base and its self-awareness of theory to transcend binary opposition that Practice Ontology Aesthetics shows, may become a helpful attempt to improve the development and construction of Chinese contemporary aesthetics. Even today, Mr. Li's Practice Aesthetics still has theoretical potential for further exploration. It is improper and arbitrary to ignore the self-breakthrough and self-creation of Practice Aesthetics and simply assert that it is obsolete or finished; While, other ones firmly defend the dogmatic and rigid understanding to Marxist Aesthetics thoughts and refuse to communicate with modern academic thoughts, which seems to adhere to the basic principle of Marxist Aesthetics, but actually make it devoid of present context and will finally lead it to a dead end. Above all, in my opinion, it is irresponsible and does no good to the construction and development for Chinese contemporary aesthetics to blame the main idea of Practice Ontology Aesthetics rudely and sometimes politically even without fundamental understanding.

In fact, the two-year discussion fully indicates that, in current aesthetical circle in China, the mode of thinking on subject-object dichotomy still has a very strong presence, the behavior that adding political reasons in academic discussion is also a common occurrence, which is not the majority of this circle. For the direction in which Chinese contemporary aesthetics goes, many domestic scholars have done some attempts and achieved gratifying successes. For example, the Higher Education Press has published several textbooks on different ways and ideas of aesthetics theory; lately, Peking University Press introduced Aesthetic Principle by Mr. Ye Lang. It is very nice for the construction of Chinese aesthetics to be diversified development, the tendency of which even the Practice Aesthetics itself should also have and have already had. For example, Mr. Deng Xiaomang and Mr. Zhang Yuneng put forward new Practice Aesthetics respectively. I believe that the future prospect of Chinese aesthetics is very broad and anticipated.

\section{References}

Li Zehou, \& Liu Xuyuan. (2011). It's Time for the Chinese Philosophy. Shanghai: Shanghai Translation Publishing House. Li Zehou. (1980). Essays on Aesthetics. Shanghai: Shanghai Literary Press.

Martin Heidegger. (1999). Being and Time. (Chen Jiaying \& Wang Qingjie, Trans.). Beijing: Joint Publishing Co.

Marx, K., \& Engels, F. (1995). Selections of K. Marx and F. Engels (Vol. 1). Beijing: People’s Publishing House. 